\title{
Klasifikasi Tingkat Kematangan Buah Kersen Menggunakan Citra HSI Dengan Metode K-Nearest Neighbor (KNN)
}

\author{
Krisna Aditya Pratama ${ }^{1}$, Wahyu Priyo Atmaja ${ }^{2}$, Veronica Lusiana ${ }^{3}$ \\ email : krisnapratama2606@gmail.com ${ }^{1}$,wahyupriyo1707@gmail.com², verolusiana@yahoo.com ${ }^{3}$ \\ Program Studi Teknik Informatika, Universitas Stikubank Semarang
}

\begin{abstract}
Abstrak
Buah kersen sering dianggap buah yang tidak bermanfaat, ternyata buah kecil ini memiliki banyak manfaat tersembunyi. Dalam artikel ini penulis ingin mengidentifikasi dan mengklasifikasi kematangan buah kersen menggunakan citra HSI dengan metode KNN. Tujuan penelitian ini adalah memberikan hasil berupa tingkat kematangan buah kersen menggunakan aplikasi matlab. Dengan menggunakan metode K-Nearest Neighbor (KNN) untuk menentukan tingkat kematangan buah kersen. Data training yang digunakan berjumlah 18 data, terdiri dari 6 data matang, 6 data setengah matang dan 6 data mentah.
\end{abstract}

Kata kunci : Matlab, KNN, HSI

\section{Pendahuluan}

Kersen merupakan tanaman yang memiliki buah kecil berwarna merah dan manis seperti buah cery. Tanaman Kersen merupakan jenis pohon yang umum sekali dijumpai di pinggir jalan. Pohon ini awalnya tumbuh liar dipinggir jalan, selokan atau bahkan sela sela rumah. Walau sekarang banyak dimanfaatkan sebagai tanaman peneduh, sebenarnya buah ini mempunyai manfaat yang sangat banyak [1].

Dalam Bahasa ilmiah buah ini diberi nama Muntingia Calabura yang masih satu keluarga dengan buah ceri. Kematangan buah kersen biasanya cukup dilihat dari perubahan warna pada kulit buahnya, biasanya buah ini memerlukan waktu sekitar 2 minggu untuk bisa matang sempurna.

Oleh karena itu, berdasarkan uraian diatas peneliti tertarik membuat program yang dapat mengidentifikasi tingkat kematangan buah kersen ini menggunakan Citra HSI dengan metode K-Nearest Neighboor (KNN) berdasarkan data training yang kita sediakan dalam penelitian yang berjudul "Klasifikasi tingkat kematangan buah kersen menggunakan Citra HSI dengan metode K-Nearest Neighbor (KNN)".

\section{Metode Penelitian}

A. Pengolahan Citra Digital

Pengolahan citra digital (Digital Image Processing) adalah sebuah ilmu yang mempelajari teknik menggolah citra. Citra yang dimaksud adalah gambar diam (foto) maupun gambar bergerak. Secara matematis, citra merupakan fungsi dengan intensitas cahaya pada dua dimensi. Agar dapat diolah dengan komputer digital, maka harus di olah secara numerik dengan nilai diskrit. [2]

\section{B. Fitur Ekstraksi}

Ekstraksi fitur merupakan proses pengolahan nilai fitur atau ciri dari sebuah citra. Ekstraksi fitur dilakukan dengan cara menghitung rata-rata setiap nilai red, green, dan blue. Hasil perhitungan RGB dari data training dan uji digunakan sebagai data inputan.[3]

\section{K-Nearest Neighbor}

Algoritma K-Nearest Neighbor (KNN) adalah sebuah metode untuk melakukan klasifikasi terhadap citra berdasarkan data training dan data uji. Algoritma KNN masuk kedalam algoritma supervised. Tujuan dari algoritma KNN adalah untuk mengklasifikasi objek berdasarkan data training dan data uji. [4]

D. HSI

Ruang warna HSI memiliki 3 dimensi ruang, yaitu Hue (H), Saturasi (S) dan Intesitas (I). Hue adalah warna dasar seperti merah, kuning, hijau dan biru atau campuran warna tersebut sedangkan Saturasi merupakan ketajaman warna pada hue. Dan Intesitas merupakan pencahayaan pada hue dan saturasi.[5] 


\section{Hasil dan Pembahasan}

Penelitian kali ini dilakukan untuk mengklasifikasi tingkat kematangan buah Kersen menggunakan citra HSI dengan metode K-Nearest Neighbor (KNN). Pada tahap penilitian ini fitur yang di gunakan adalah fitur warna R, G, B kemudian akan melalui proses ekstrasi menjadi citra HSI dan di klasifisikan menggunakan metode $\mathrm{K}$ Nearest Neighbor (KNN). Alur dari algoritma KNN seperti dalam Gambar 1.

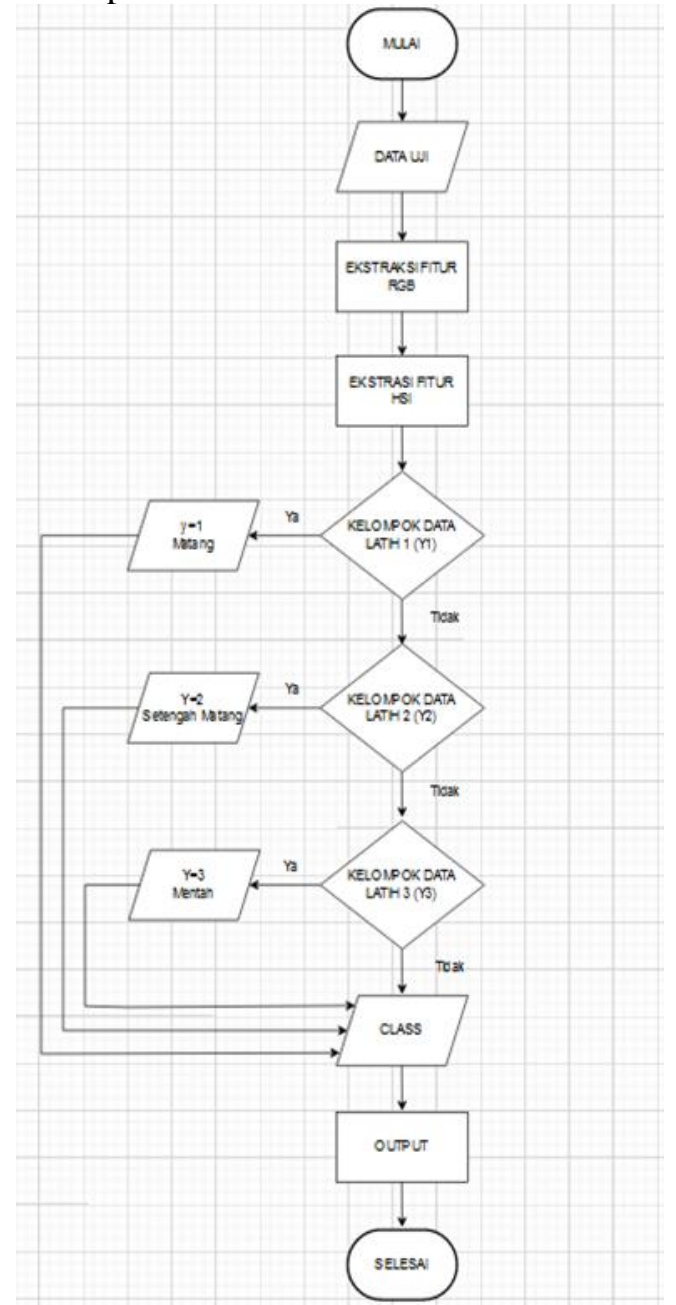

[6]

Gambar 1. Diagram Alur Metode K-NN

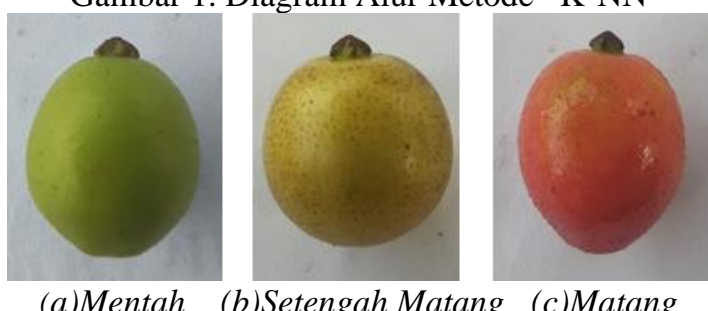

(a)Mentah (b)Setengah Matang (c)Matang

Gambar 2. Sample Citra Buah Kersen

Berdasarkan Gambar 2, citra buah kersen dalam penelitian ini menggunakan format .jpg dengan total data 27 buah yang terdiri dari 18 data training/latih dan 9 data uji diuji dan dibagi menjadi 3 tingkat kematangan yaitu Mentah, Setengah Matang, dan Matang. Data citra diambil pada backgroud warna putih dengan menggunakan kamera macro Redmi 9 beresolusi 5 megapiksel dengan jarak $5 \mathrm{~cm}$ dari kamera. Setiap citra akan dilakukan pembagian menjadi komponen red, green, dan blue untuk diekstraksi menggunakan fitur RGB dan kemudian diekstraksi lagi menggunakan citra HSI. Hasil ekstraksi fitur data latih dan data uji digunakan sebagai inputan proses klasifikasi untuk menentukan tingkat kematangan dari buah kersen berdasarkan fitur warna. Teknik klasifikasi dan ekstraksi fitur dilakukan dengan Matlab R2021b. Algoritma yang digunakan adalah KNearest Neighbor dengan nilai $k=1,3$ dan 5 . Untuk metode yang kami gunakan untuk mengklasifikasi buah kersen dari tingkat kematangannya berdasarkan fitur warna ditunjukkan pada gambar 3. [7]

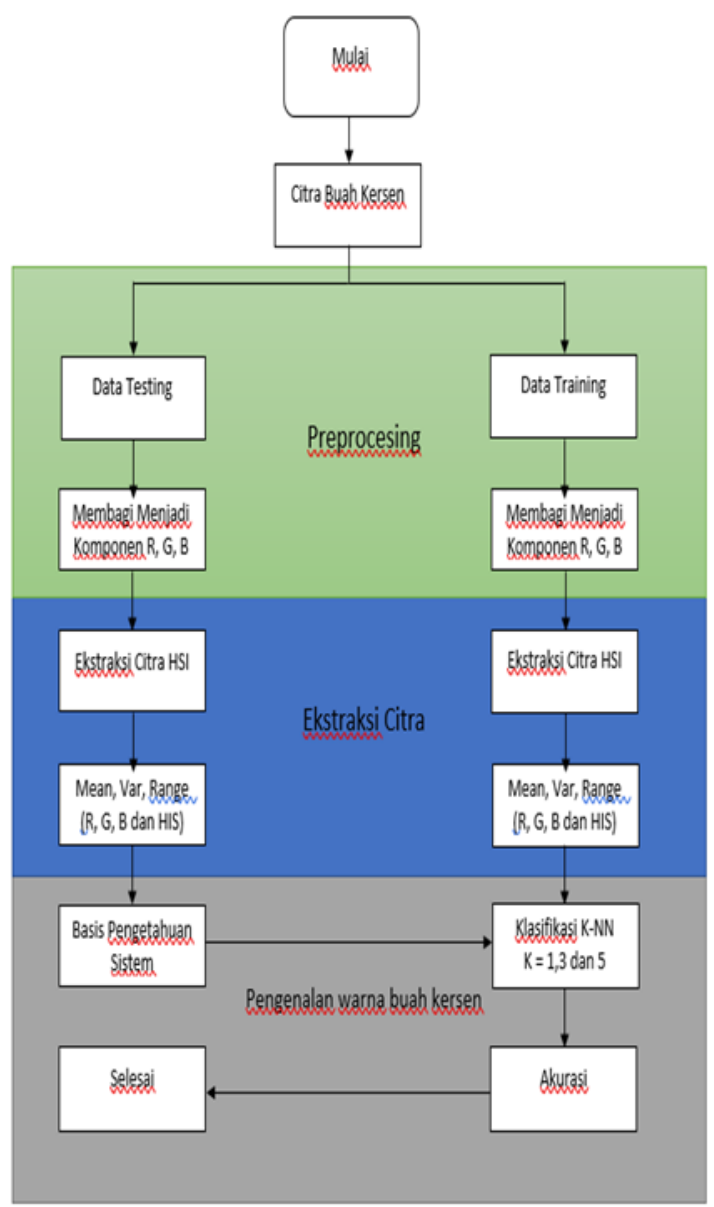

Gambar 3. Metode Klasifiksi Buah Kersen Menggunakan Metode K-NN

Pengujian dilakukan dengan 3 kali percobaan, yaitu dengan $\mathrm{k}=1,3$, dan 5 . Pengujian yang kami lakukan yaitu 
menggunakan data training/latih dan data testing Berikut ini hasil pengujian yang dengan menggunakan data training/latih.

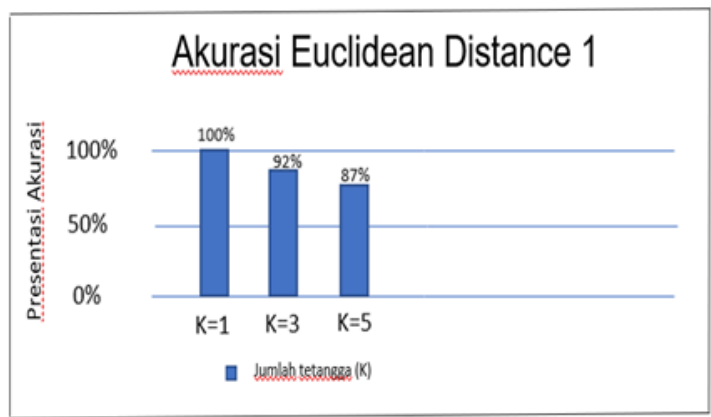

Gambar 4. Perhitungan Akurasi Data

Training/Latih Menggunakan Euiclidean Distance

Dari gambar 4 menunjukan bahawa akurasi tertinggi yang didapatkan saat melakukan pengujian pada data training/latih yaitu pada $\mathrm{k}=1$ yang mendapatkan nilai akurasi $100 \%$, sehingga system pengujian layak digunakan.

Tingkat Akurasi $=\frac{\text { jumlah data yang terklasifikasi dengan benar }}{\text { jumlah total data citra uji }} \times 100 \%$

$$
\text { Akurasi }=8 / 9 * 100 \%=89 \%
$$

Berdasarkan hasil pengujian dengan citra uji sebanyak 9 data, dari 9 data citra yang dilakukan pengujian ada 8 data citra yang outputnya sesuai dan ada 1 data citra yang outputnya tidak sesuai. Berdasarkan rumus diatas maka tingkat keakuratan alogritma KNN sebesar $89 \%$.

Tabel 1 menunjukan bahwa citra buah kersen setengah matang memiliki kemiripan warna dengan data citra matang. Sedangkan pada citra buah kersen mentah dan matang telah diklasifikasikan dengan benar

\begin{tabular}{|c|c|c|c|}
\hline $\begin{array}{l}\text { No uji } \\
\text { Citra }\end{array}$ & Input & Output & Target \\
\hline 1 & Mentah & Mentah & \multirow[t]{3}{*}{ Mentah } \\
\hline 2 & Mentah & Mentah & \\
\hline 3 & Mentah & Mentah & \\
\hline 4 & $\begin{array}{c}\text { Setengah } \\
\text { Matang }\end{array}$ & $\begin{array}{c}\text { Setengah } \\
\text { Matang }\end{array}$ & \multirow[t]{3}{*}{$\begin{array}{l}\text { Setengah } \\
\text { Matang }\end{array}$} \\
\hline 5 & $\begin{array}{c}\text { Setengah } \\
\text { Matang }\end{array}$ & $\begin{array}{c}\text { Setengah } \\
\text { Matang }\end{array}$ & \\
\hline 6 & $\begin{array}{c}\text { Setengah } \\
\text { Matang }\end{array}$ & Matang & \\
\hline 7 & Matang & Matang & \multirow[t]{3}{*}{ Matang } \\
\hline 8 & Matang & Matang & \\
\hline 9 & Matang & Matang & \\
\hline
\end{tabular}

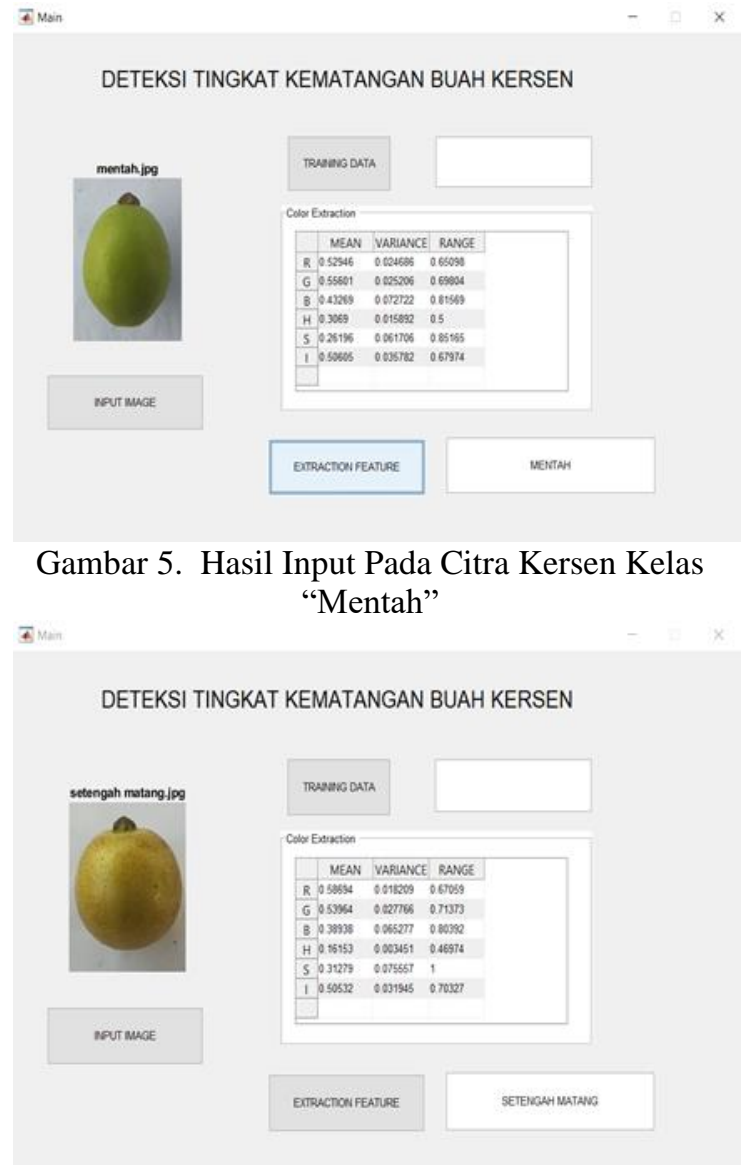

Gambar 6. Hasil Input Pada Citra Kersen Kelas "Setengah Matang"

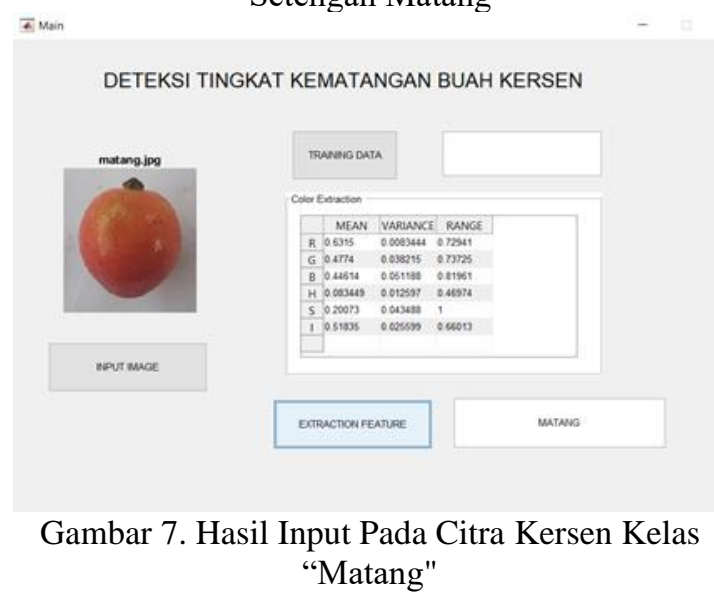

\section{Kesimpulan}

Berdasarkan hasil pengujian yang di lakukan untuk mengklasifikasi kematangan buah kersen berdasarkan fitur warna menggunakan citra HSI dengan metode K-Nearest Neighbor dapat diambil kesimpulan bahwa metode K-Nearest Neighbor dapat diterapkan untuk mengklasifikasi kematangan buah kersen berdasarkan fitur warna menggunakan 
citra HSI. Berdasarkan hasil pengujian dengan citra uji sebanyak 9 data citra, akurasi yang di hasilkan cukup tinggi yaitu sebesar $89 \%$.

\section{Daftar Pustaka}

[1] Meiliza, Esty Rizki and, Dra. Hariyatmi, M.Si, Pengaruh Jus Buah Kersen (Muntingia calabura L) Terhadap Kadar Asam Urat Darah Mencit (Musmusculus). Skripsi thesis, Universitas Muhammadiyah Surakarta, 2013.

[2] RD. Kusumanto, Alan Novi

Tompunu, Pengolahan Citra Digital

Untuk Mendeteksi Obyek

Menggunakan Pengolahan Warna

Model Normalisasi RGB, Politeknik

Negeri Sriwijaya, 2011.

[3] Shinta Aprilisa, Sukem, Klasifikasi

Tingkat Kematangan Buah Tomat

Berdasarkan Fitur Warna

Menggunakan K-Nearest Neighhbor.

Universitas Sriwijaya, Palembang, 2019.

[4] Febri Liantoni, Klasifikasi Daun

Dengan Perbaikan Fitur Citra

Menggunakan Metode K-Nearest

Neighbor. Institut Teknologi Adhi

Tama, 2015.

[5] Wanvy Arifha Saputra, Agus Zainal Arifin, Seeded Region Growing pada

Ruang Warna HSI untuk Segmentasi

Citra Ikan Tuna, Institut Teknologi

Sepuluh Nopember Surabaya, 2017.

[6] Shinta Aprilisa, Sukem, Klasifikasi

Tingkat Kematangan Buah Tomat

Berdasarkan Fitur Warna

Menggunakan K-Nearest Neighhbor.

Universitas Sriwijaya, Palembang, 2019.

[7] Shinta Aprilisa, Sukem, Klasifikasi

Tingkat Kematangan Buah Tomat

Berdasarkan Fitur Warna

Menggunakan K-Nearest Neighhbor.

Universitas Sriwijaya, Palembang, 2019.

[8] Shinta Aprilisa, Sukem, Klasifikasi

Tingkat Kematangan Buah Tomat
Berdasarkan Fitur Warna

Menggunakan K-Nearest Neighhbor.

Universitas Sriwijaya, Palembang, 2019 